\title{
Rehabilitación de la estructura de un antiguo hotel para su utilización como banco
}

\author{
A. Payer ${ }^{1}$, V. De Nápoli ${ }^{1}$, D. Hünicken ${ }^{1}$, H. Gattavara ${ }^{1}$ \\ ${ }^{1}$ Universidad Nacional de Córdoba, Córdoba, Argentina.
}

\section{Información del artículo} DOI:

http://dx.doi.org/10.21041/ra.v2

$$
\underline{i 1.22}
$$

Artículo recibido el 20 de Septiembre de 2011, revisado bajo las políticas de publicación de la Revista ALCONPAT y aceptado el 18 de Noviembre de 2011. Cualquier discusión, incluyendo la réplica de los autores se publicará en el tercer número del año 2012 siempre y cuando la información se reciba antes del cierre del segundo número del año 2012

C 2012 Alconpat Internacional

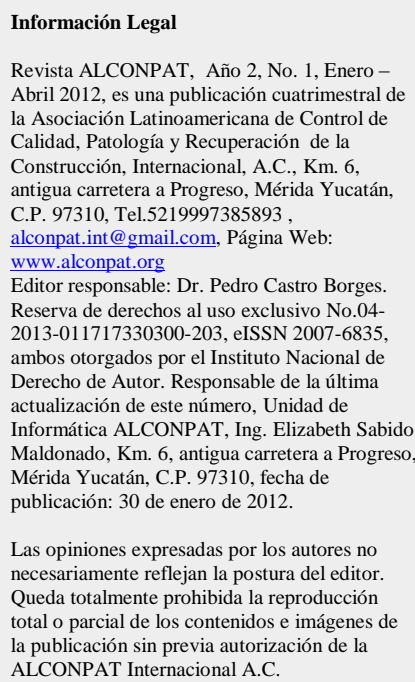

\section{RESUMEN}

En el presente trabajo se muestra el proyecto mediante el cual se adecuó la estructura del edificio de un hotel de 100 años de antigüedad para su utilización como institución bancaria. La estructura resistente del antiguo edificio estaba materializada por muros de mampostería con algunas columnas metálicas en su interior, los entrepisos y techos son de perfiles metálicos con bovedillas de mampostería cerámica. Se debían mantener las fachadas y los entrepisos y techos originales. Por otra parte, había que demoler gran parte de los muros interiores portantes.

Ante esta situación se tuvo que:

- Reforzar los muros de mampostería que no se demolían;

- Diseñar la estructura de reemplazo de los muros a demoler;

- Y diseñar nuevas estructuras para garantizar la estabilidad del nuevo edificio terminado y durante su construcción, de acuerdo a las normativas actuales.

Palabras clave: rrehabilitación; modelo; diafragma rígido; estabilidad espacial.

\section{ABSTRACT}

A project of rehabilitation of a 100 years old building is presented. The structure of the old building consisted of masonry walls with some metal columns inside them, the slabs and ceilings have metal girders with small arches made of ceramic bricks. The original facades, slabs and ceilings were to be kept. On the other hand, to adapt the building to de new destination, most of the load-bearing walls were to be removed.

Before these requirements the following was decided:

- To make stronger the non-removed masonry walls.

- To design a replacement structure for the removed walls.

- To design new structures that guarantee the stability of the new building during and after construction, in accordance to standards.

Key words: rehabilitation; model; rigid diaphragm; spatial stability.

Autor de contacto: Alfredo Payer (alfredopayer@hotmail.com) 


\section{INTRODUCCION}

En la ciudad de Córdoba (República Argentina), frente a la plaza principal, está ubicado el Edificio construido a comienzos del siglo XX para hotel. Durante sus más de cien años de vida funcionó al comienzo como Hotel Palace, luego fue sede de la Municipalidad, Geriátrico y Oficinas. Los distintos usos le ocasionaron algunas modificaciones a la construcción original, fundamentalmente en la fachada del primer nivel (Figura 1).

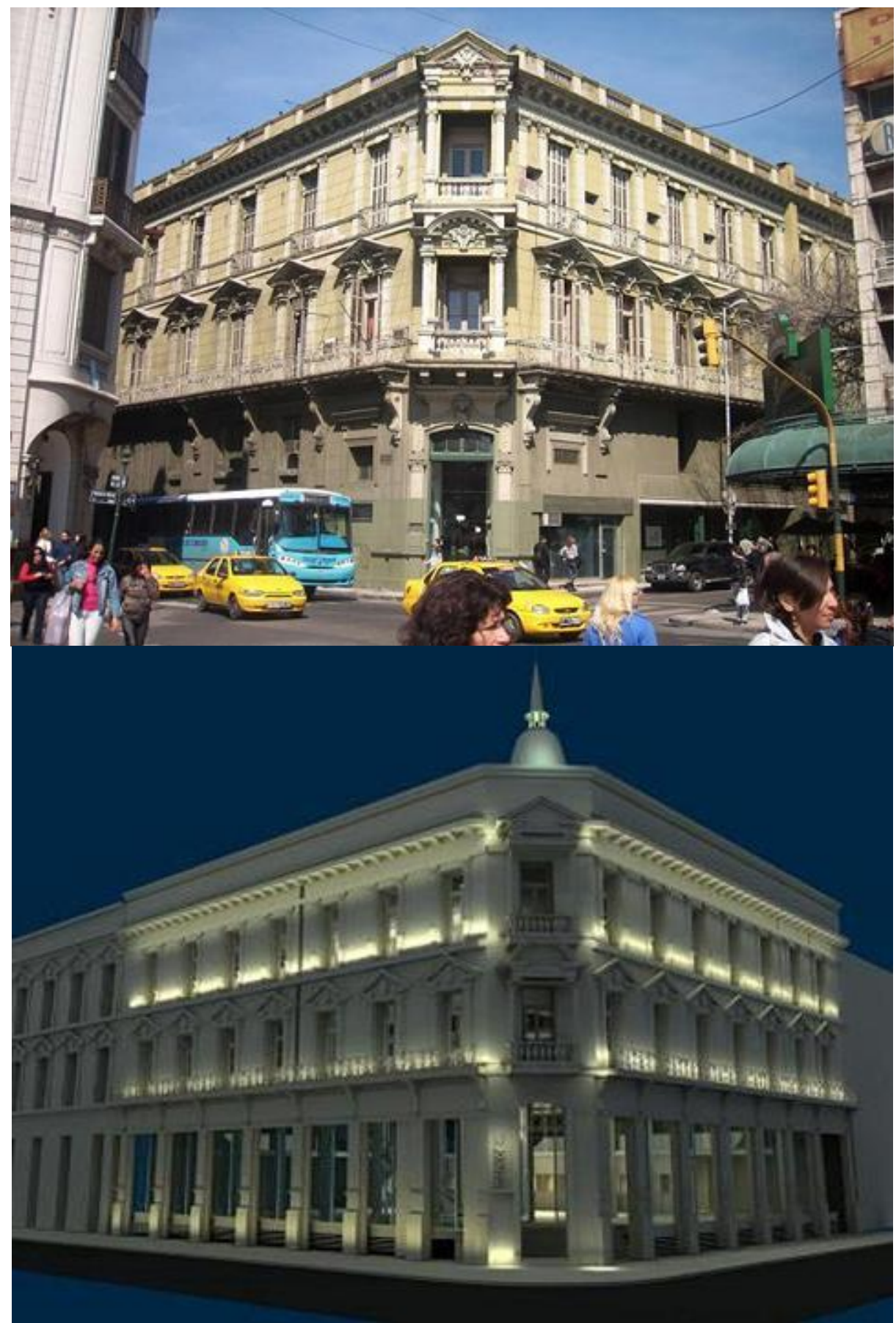

Figura 1. Fachada actual y Fachada Refuncionalizada. 
Su actual propietario, el Banco de la Provincia de Córdoba, quiere rescatarlo para trasladar a este edificio una de sus sucursales.

A tales efectos, se realizó un concurso de Anteproyectos, el que fue ganado por el Estudio Díaz Arquitectos Asociados.

La recuperación de este tradicional edificio tendrá un significativo impacto cultural para la Ciudad de córdoba, tanto por su historia como por el rol protagónico del Banco en esa ubicación. Se tomaron como premisas básicas para la elaboración del proyecto, la recuperación de los valores esenciales del edificio (como sus fachadas) y la tipología estructural de su patio interior. Las fachadas serán restauradas con rigor en los niveles superiores, donde no han sufrido intervenciones. En el primer nivel, con importantes modificaciones, se reconstruirán todos los pilares originales con mampostería y hormigón armado y se colocará una piel acristalada en las aberturas.

También se conserva el núcleo circulatorio existente de ascensor y escalera de mármol de carrara.

\section{DESCRIPCIÓN DE LA ESTRUCTURA RESISTENTE DEL ACTUAL EDIFICIO}

En el actual edificio la estructura resistente está constituida por muros de mampostería resistentes en todo su perímetro (medianeros y de fachada). Los muros son de mampostería de ladrillos cerámicos macizos de espesor variable en altura, comenzando con espesores de 60 a $75 \mathrm{~cm}$ en primer nivel y 30 a $45 \mathrm{~cm}$ en el tercer nivel.

A nivel de subterráneo existe un muro perimetral de $80 \mathrm{~cm}$ de espesor que contiene el suelo exterior y soporta toda la mampostería perimetral.

En el interior existen muros portantes y muros no portantes, como así también columnas metálicas de sección anular que soportan cargas gravitatorias. Estas columnas se encuentran principalmente en el subterráneo, en algunas zonas de primer nivel y en la galería del $2^{\circ}$ y $3^{\circ}$ nivel.

Los entrepisos y techo están materializados por perfiles doble Te que soportan una estructura de ladrillos con forma abovedada más el relleno de nivelación de los diferentes pisos. Estos perfiles apoyan en muros portantes o en vigas metálicas formadas por dos a cuatro perfiles doble Te que apoyan en columnas y muros portantes.

Como los requerimientos del nuevo destino obligan a la demolición de una cantidad importante de muros portantes, los que además de soportar las acciones gravitatorias garantizan la estabilidad del edificio ante fuerzas laterales de viento y sismo. Se debieron diseñar nuevas estructuras que reemplacen a las que se demuelen.

\section{TAREAS INICIALES}

Para elaborar el proyecto de la estructura resistente del edificio refuncionalizado se debieron realizar en un comienzo las siguientes tareas.

- Relevamiento de la estructura: Al carecer totalmente de documentación se tuvo que realizar un detallado relevamiento para identificar la estructura resistente del antiguo edificio. Se relevaron muros portantes y no portantes, columnas metálicas, perfiles de vigas y losas de entrepisos y cubierta. También se realizaron tres excavaciones para relevar las estructuras de fundación. Toda esta información se ha llevado a planos (Figura 2).

- Estudios de suelo: Para verificar las estructuras de fundación actuales y proyectar las a construir, se realizó un estudio de suelos. 
Revista ALCONPAT, Volumen 2, Número 1, Enero - Abril 2012, Páginas 10 - 20

- Modelación de la estructura: Con la información obtenida en el relevamiento se confeccionó un modelo numérico tridimensional para representar el comportamiento de la estructura frente a las cargas gravitatorias actuales y la acción sísmica de diseño. El modelo de la estructura existente permite determinar el estado tensional de los muros de mampostería y las solicitaciones en columnas, así como los esfuerzos transmitidos a la fundación y el grado de rigidez global de la estructura.

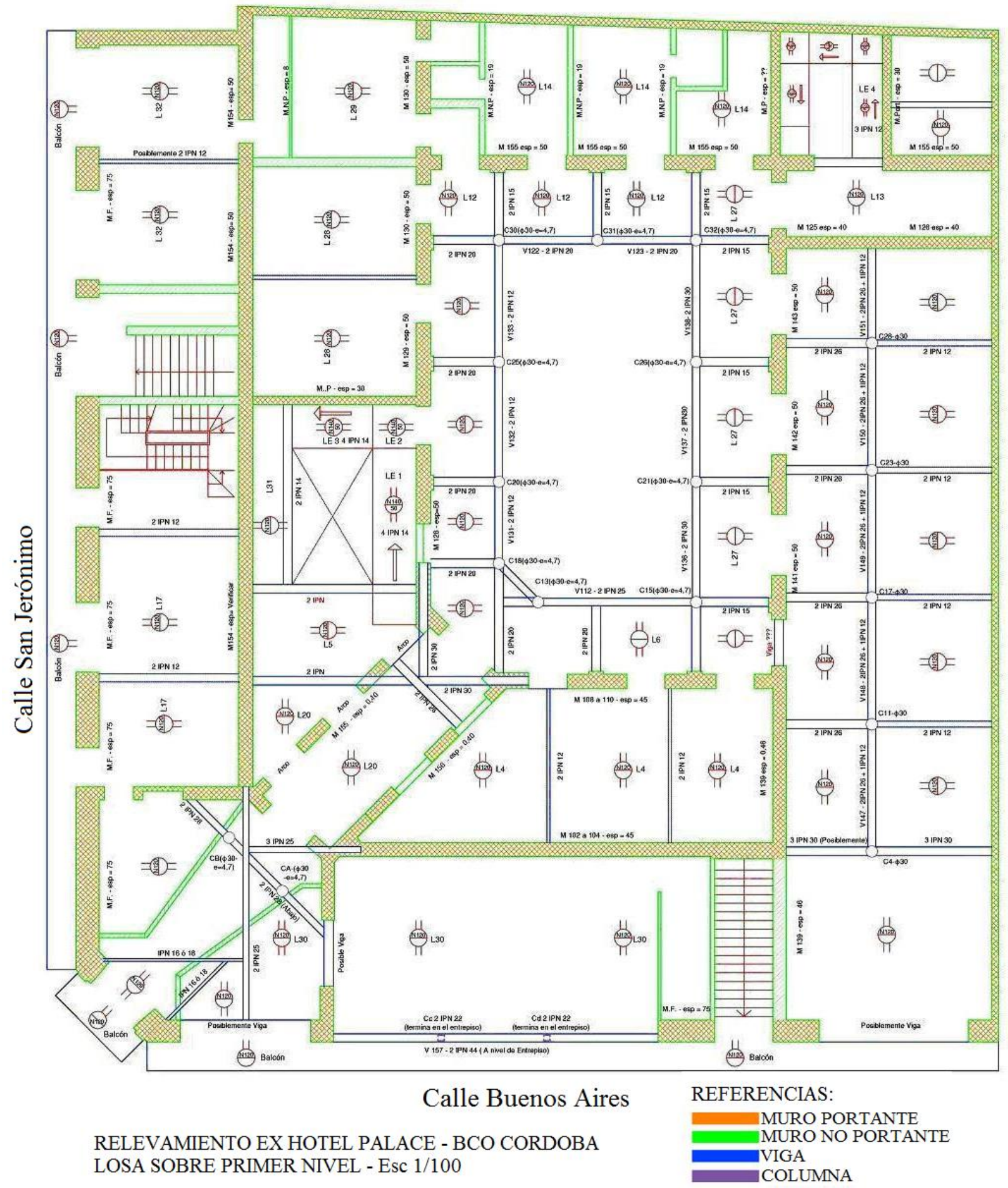

Figura 2. Plano de relevamiento de primer nivel. 


\section{PROYECTO DE LA ESTRUCTURA DEL EDIFICIO REFUNCIONALIZADO}

Como ya lo mencionáramos al describir la actual estructura resistente del edificio, el proyecto de refuncionalización exige la demolición de una importante cantidad de muros portantes y no portantes. En el subterráneo se demuelen pocos muros porque en este nivel existen muchas columnas metálicas, pero en primer, segundo y tercer nivel se eliminan la mayoría de los muros interiores. También se deben construir nuevas estructuras para las circulaciones verticales (escaleras y ascensores). Otro requerimiento es la conservación de casi todos los entrepisos y techos existentes, como así también de la escalera y del ascensor.

Estos condicionantes nos colocan en la siguiente situación: debemos construir las estructuras resistentes que garanticen la estabilidad espacial del edificio antes de proceder a la demolición de los muros, ya que pensar en apuntalamientos generalizados sería operativamente imposible. Frente a estos requerimientos, para materializar la estructura resistente se proponen las siguientes tareas:

a) Reforzar los muros portantes que se demuelen parcialmente.

b) Construir nuevas estructuras de pórticos y tabiques para reemplazar a los muros portantes que se demuelen.

c) Materializar en los entrepisos y en la cubierta diafragmas rígidos horizontales de hormigón armado vinculados con conectores a los perfiles para que sirvan de apoyo a los muros de mampostería y transmitan las fuerzas horizontales a los distintos elementos resistentes.

d) Construcción de los núcleos de circulación verticales que contempla el nuevo proyecto.

\subsection{Modelación numérica de la estructura existente}

Para analizar el comportamiento de la estructura existente se emplea un modelo tridimensional donde se representan con elementos tipo placas los muros de mampostería portante y con elementos de barras las vigas y columnas de la construcción. La Figura 3 muestra una perspectiva del modelo construido.

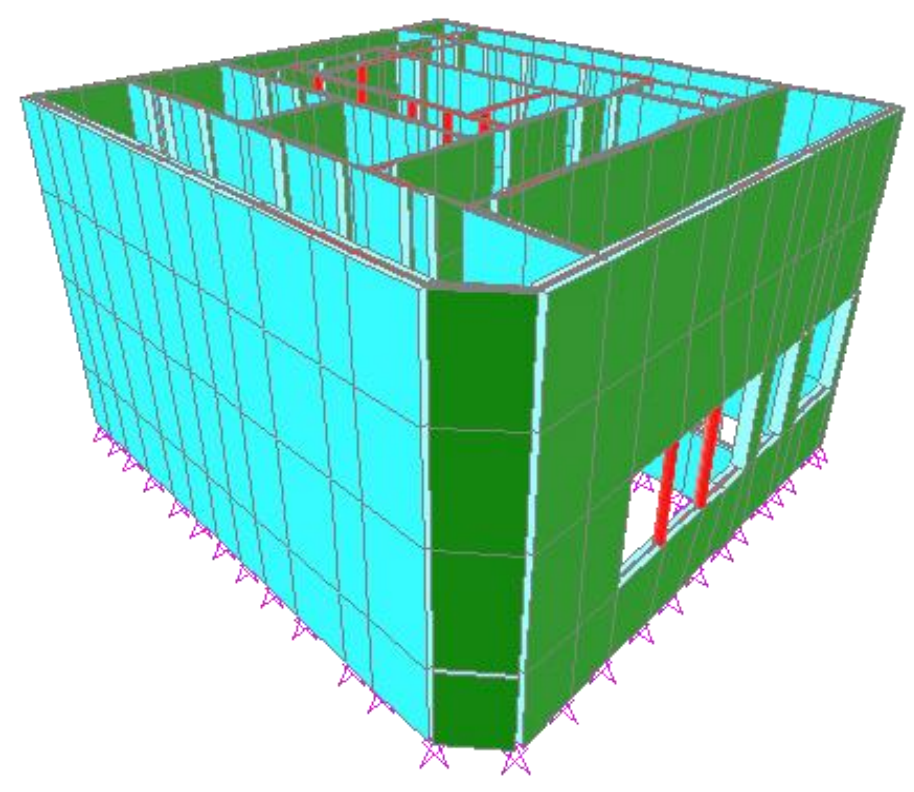

Figura 3. Modelo numérico. Vista 3D. 


\subsection{Análisis estructural}

Con el modelo se realiza un análisis dinámico para estimar los períodos dominantes de la construcción y un análisis estático para estimar las solicitaciones en la mampostería y los esfuerzos sobre las fundaciones del edificio.

Análisis dinámico. Se realiza un análisis modal para determinar los períodos fundamentales de la estructura los cuales brindan información sobre la rigidez de la estructura y permiten definir las solicitaciones sísmicas de diseño. Los valores obtenidos son los siguientes: Modo traslacional (calle Bs. As.) 0,202 s, Modo traslacional (calle San Jerónimo) 0,169 s, Modo rotacional 0,128 s. De los resultados obtenidos de deduce que se trata de una estructura con elevada rigidez en las dos direcciones principales, los cual se justifica por el espesor y la densidad de muros resistentes y por el bajo número de niveles de la construcción. En la Figura 4 se presentan las formas modales traslacionales y rotacionales del edificio.

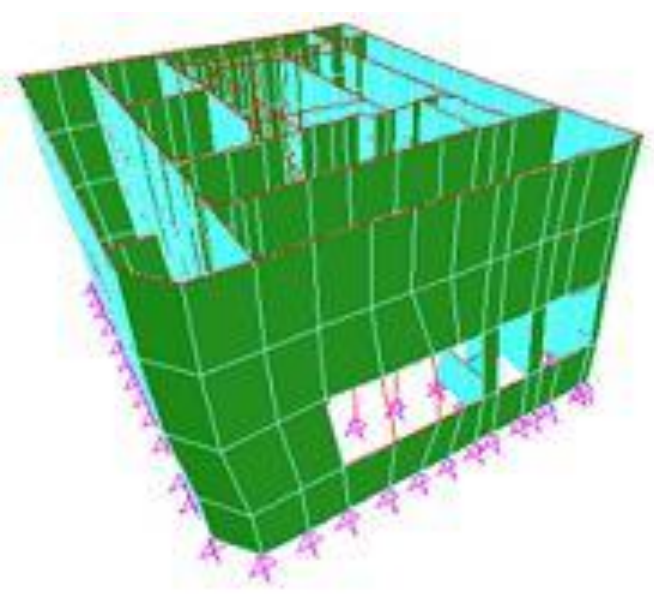

a) Modo traslacional. $\mathrm{T} 1=0.202 \mathrm{~s}$

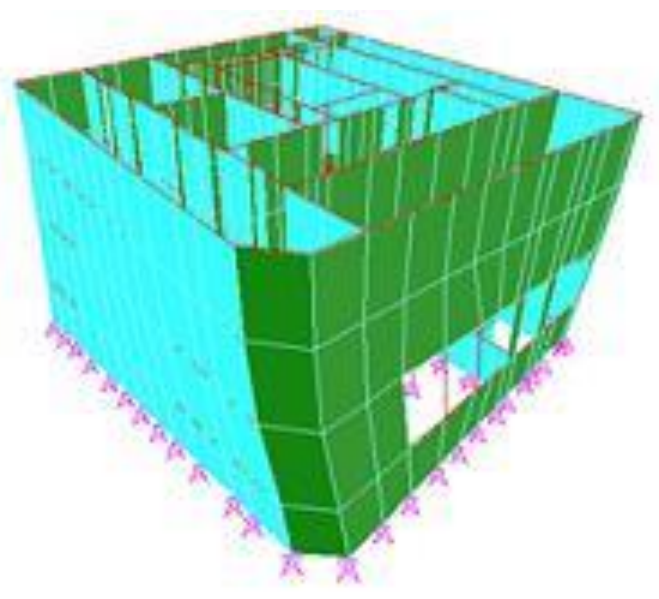

b) Modo rotacional. T3=0.128 s

Figura 4. Modos de vibración.

4.2.1 Solicitaciones en muros. El modelo permite estimar las tensiones de trabajo de la mampostería en los diferentes niveles. Según los resultados obtenidos, la tensión de trabajo de la mampostería es del orden de 0,4 a $0,5 \mathrm{MPa}$, lo cual se considera bajo y justificado por los espesores de los muros resistentes.

4.2.2 Solicitaciones axiales en columnas. Las cargas gravitatorias en columnas son cargas moderadas sobresaliendo 4 columnas con solicitaciones de 1350, 1200, 1100 y $1000 \mathrm{kN}$, mientras que el resto soporta esfuerzos axiales inferiores a $800 \mathrm{kN}$.

Por lo anterior se considera viable la posibilidad de intervenir en las zonas de demolición y remodelación diseñando pórticos y refuerzos en mampostería que permitan redistribuir los esfuerzos axiales.

4.2.3 Verificación de la fundación. De la auscultación realizada a las fundaciones se observó que el muro perimetral de $90 \mathrm{~cm}$ tiene un cimiento corrido de $1.30 \mathrm{~m}$ de ancho. Según los resultados obtenidos, esta mampostería podría trabajar a una tensión de 0,5 MPa lo que representa una tensión de trabajo para el suelo del orden de 0,21 MPa. Debería confirmarse si la cota de fundación de este cimiento es el manto de arena ubicado a los $5.0 \mathrm{~m}$ de profundidad desde el terreno natural.

Por otra parte se realizó la auscultación de una base de columna. Se recomienda realizar la auscultación de las bases más solicitadas. 


\subsection{Modelación numérica de la estructura refuncionalizada}

El modelo de elementos finitos original es modificado para representar la estructura refuncionalizada del edificio. Para ello se eliminan elementos que representan muros de mampostería a demoler, columnas del patio central, se agregan pórticos metálicos y núcleos de tabiques de hormigón destinados a resistir las solicitaciones laterales y rigidizar el edificio.

La Figura 5 muestra una comparación entre el modelo original y el modificado donde son evidentes todas las intervenciones proyectadas sobre la estructura y su adecuación con el planteo arquitectónico final.

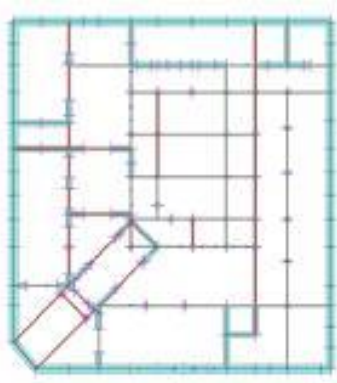

a.1) Losa sobre subterráneo

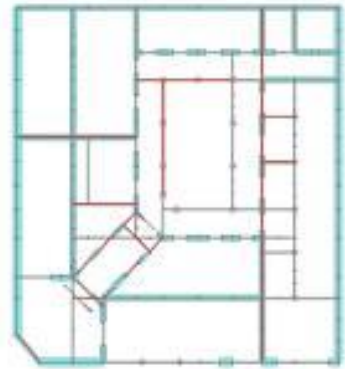

a.2) Losa sobre subterráneo readecuada

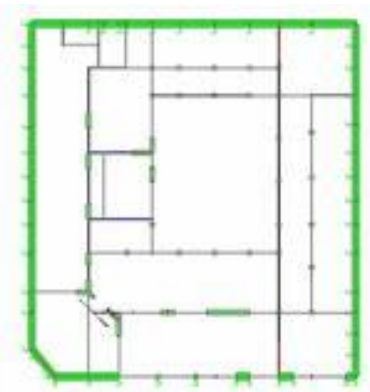

b.1) Losa sobre primer nivel

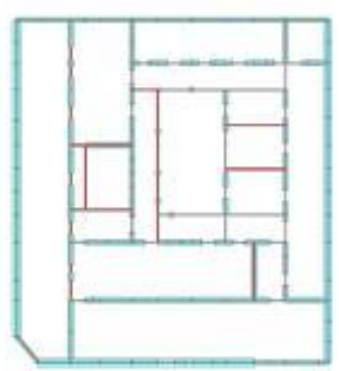

c.1) Losa sobre $2^{\circ}$ y $3^{\circ}$ nivel

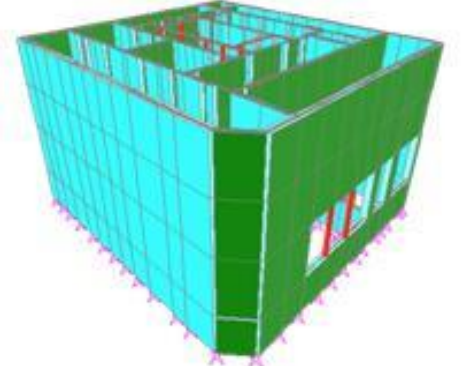

Vista 3D estructura actual

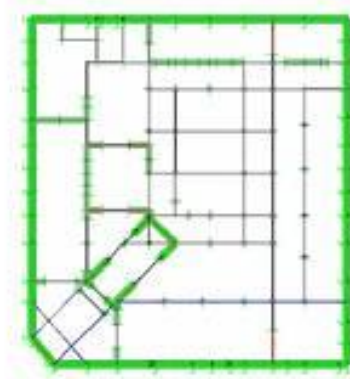

b.2) Losa sobre primer nivel readecuada

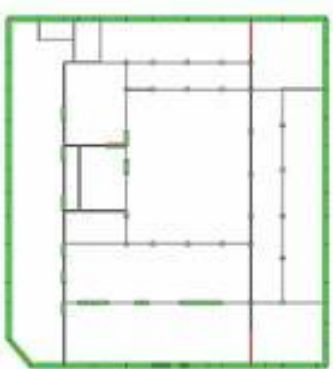

c.2) Losa sobre $2^{\circ}$ y $3^{\circ}$ nivel readecuada

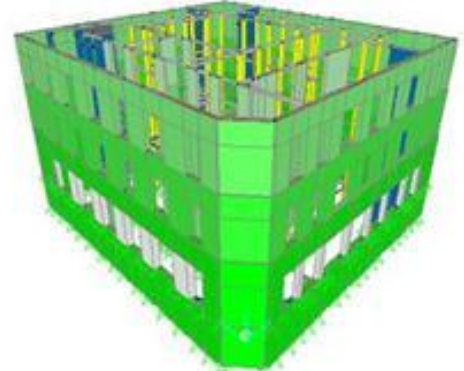

Vista 3D estructura readecuada

Figura 5. Comparación entre modelos numéricos. 


\subsection{Solicitaciones de diseño}

4.4.1 Muros de Mampostería. Con respecto a las cargas gravitatorias, la diferencia más significativa es la eliminación de importantes paños de mampostería que constituye una diferencia del orden de $20000 \mathrm{kN}$. Asimismo, se diseñan núcleos de tabiques sismorresistentes cuya fundación es independiente de los cimientos y bases de la estructura original.

4.4.2 Losas de entrepiso y de cubierta. En cuanto a las losas se propone retirar el relleno por encima de las bovedillas hasta la altura superior de los perfiles, donde se proyecta una carpeta de compresión de $10 \mathrm{~cm}$ de espesor la cual se diseña como un diafragma rígido.

Para las losas se considera un incremento del peso propio debido a la ejecución de la carpeta, menos el relleno a remplazar, lo que representa un peso propio del orden de 4,6MPa. La sobrecarga de diseño se adopta igual a 3,5 $\mathrm{MPa}$ correspondiente a salones de reuniones sin asientos fijos y oficinas.

\subsection{Análisis estructural}

4.5.1 Análisis dinámico. Se realiza un análisis modal para determinar los períodos fundamentales de la estructura los cuales brindan información sobre la rigidez de la estructura y permiten definir las solicitaciones sísmicas de diseño. Los valores obtenidos son los siguientes: Modo traslacional (calle Bs. As.) 0,202 s y 0,451 s, Modo traslacional (calle San Jerónimo) 0,169 s y 0,352 s, Modo rotacional $0,128 \mathrm{~s}$ y $0,212 \mathrm{~s}$.

Los resultados del análisis dinámico indican, como era esperado, una disminución en la rigidez lateral del edificio por la disminución de la densidad de mampostería. Sin embargo esta disminución de rigidez no genera problemas de distorsión por la elevada rigidez inicial.

En las figuras siguientes (Figura 6) se observa que el modo más afectado por el aumento de flexibilidad es el modo traslacional en el sentido de la calle Buenos Aires, donde se reduce la densidad de muros tanto en el interior como en fachada. En el sentido de calle San Jerónimo es evidente el beneficio logrado con los núcleos de tabiques de hormigón y el pórtico metálico.

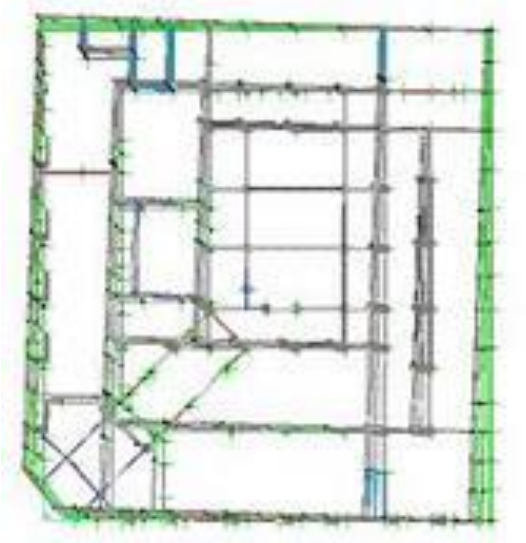

a) Modo traslacional. $\mathrm{T} 1=0.451 \mathrm{~s}$

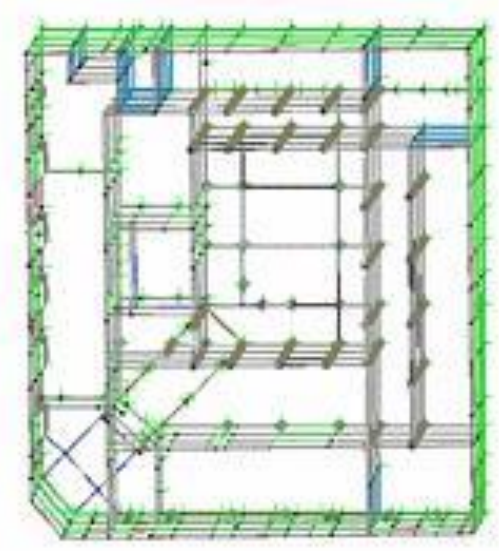

b) Modo traslacional. $\mathrm{T} 2=0.352 \mathrm{~s}$

Figura 6. Modos de vibración de la estructura refuncionalizada.

4.5.2 Solicitaciones axiales en columnas. Se observa una disminución significativa de las cargas gravitatorias en las columnas, por lo que se descarta la necesidad de realizar submuraciones en las fundaciones existentes (Figura 7). 


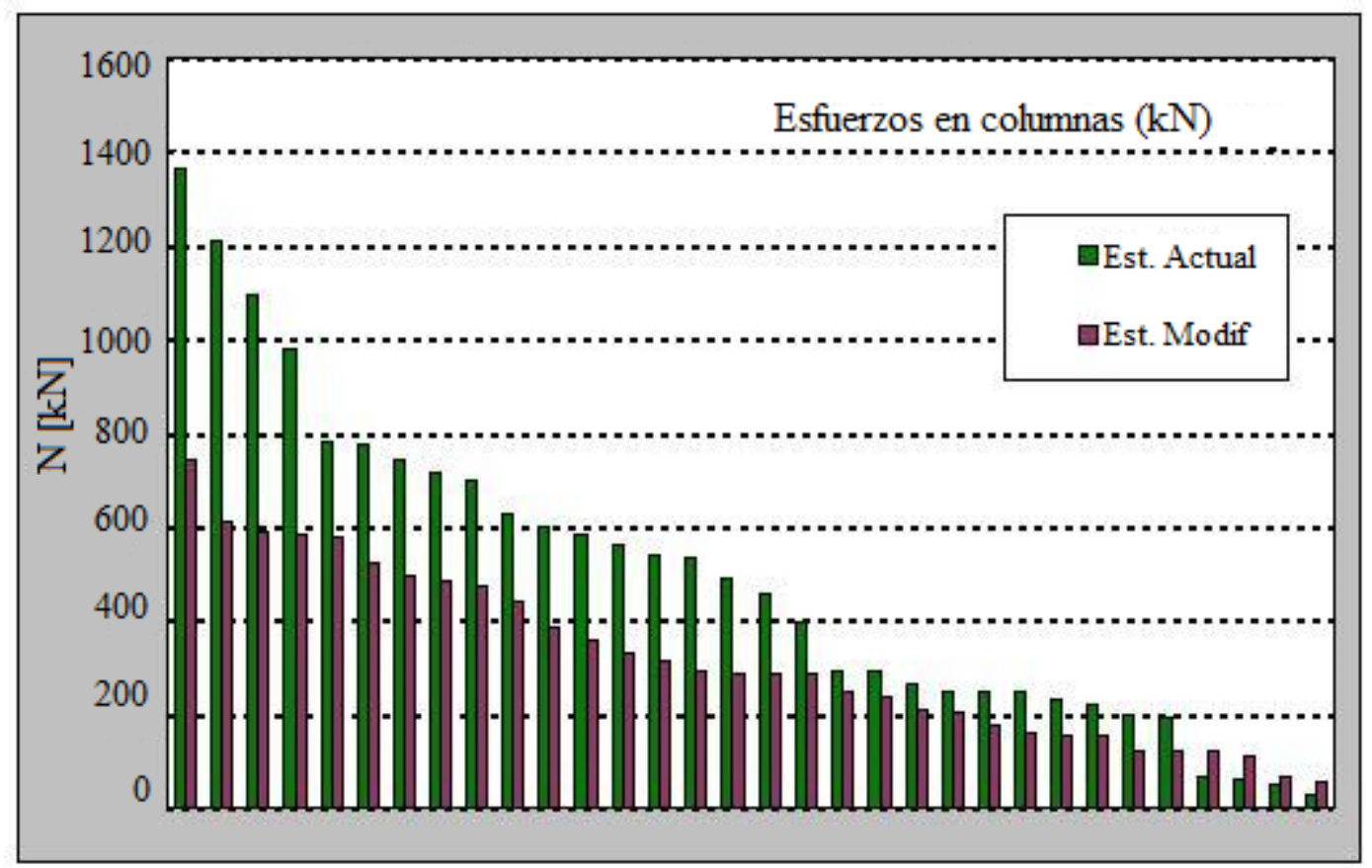

Figura 7. Esfuerzos axiales en columnas de subterráneo.

\section{PROCEDIMIENTO CONSTRUCTIVO}

En la estructura existente los muros de mampostería soportan las acciones gravitatorias y también le confieren a la estructura la resistencia y rigidez necesarias para soportar las acciones laterales de viento y sismo. Por este motivo, no se puede realizar la demolición de los mismos sin antes construir la estructura resistente que los reemplace. Tampoco se puede pensar en un apuntalamiento generalizado del edificio porque este impediría trabajar en el interior del mismo. Ante esta situación, se propuso realizar demoliciones parciales en las zonas donde se construyen los nuevos núcleos de circulación vertical y también donde se amplía el patio central, y demoliciones localizadas que permitan ubicar las columnas metálicas nuevas.

Se deberá realizar el apuntalamiento que garantice la estabilidad de la estructura en estos sectores. Luego se comenzarán a construir las nuevas estructuras desde sus fundaciones. Se ejecutarán pozos romanos, tabiques, columnas y losas de hormigón armado, y columnas y vigas metálicas. En Figura 8 se muestra la nueva estructura en primer nivel.

Cuando las nuevas estructuras hayan alcanzado el nivel de la losa sobre tercer nivel (techo), se construirá sobre los perfiles metálicos de la misma una losa de hormigón armado convenientemente vinculada a la estructura resistente que funcionará como diafragma rígido horizontal.

En esta situación se podrán demoler los muros de tercer nivel para después ejecutar una losa de hormigón armado sobre el segundo nivel, luego se demuelen los muros sobre segundo nivel y con esta secuencia se llega hasta el subterráneo. 
Revista ALCONPAT, Volumen 2, Número 1, Enero - Abril 2012, Páginas 10 - 20

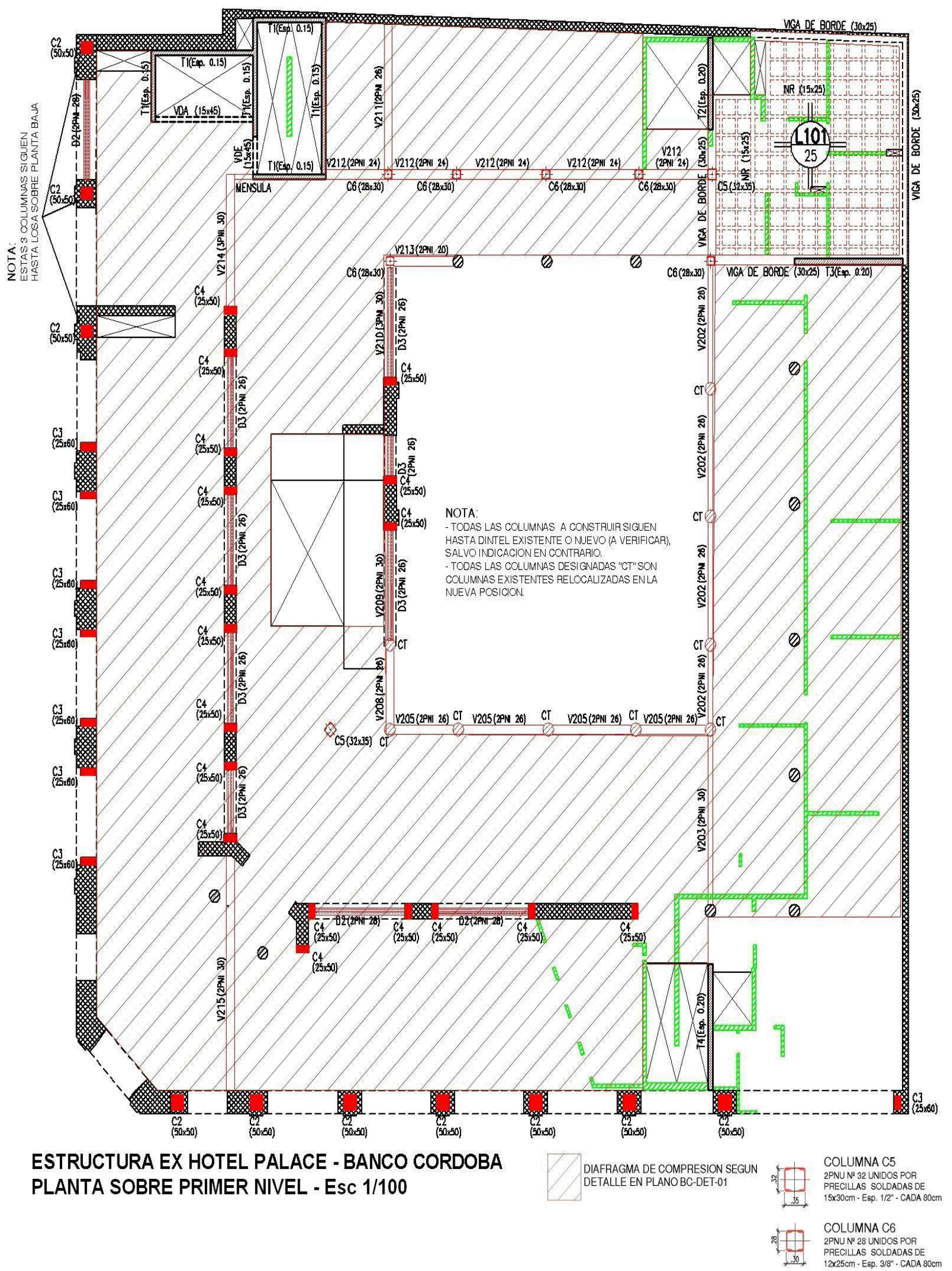

Figura 8. Plano de estructura nueva en primer nivel. 
Revista ALCONPAT, Volumen 2, Número 1, Enero - Abril 2012, Páginas 10 - 20

\section{CONCLUSIONES Y RECOMENDACIONES FINALES}

El análisis estructural realizado permite arribar a las siguientes conclusiones.

Se verifica que en todas las cimentaciones existentes las solicitaciones gravitatorias nuevas son menores que las cargas del edificio actual, ya que si bien se prevé la ejecución de un diafragma de hormigón de $10 \mathrm{~cm}$ en los diferentes niveles, los muros a demoler más el relleno que deberá eliminarse para ejecutar la carpeta de hormigón tienen un peso propio más significativo. La ejecución de las pasarelas peatonales más la cubierta cenital en el patio son de estructuras metálicas con un mucho menor peso que los sectores centrales a demoler.

Si bien la demolición de una cantidad significativa de muros resistentes representa una disminución de la rigidez lateral del edificio, los núcleos verticales de hormigón, los muros perimetrales que se conservan y refuerzan, más la ejecución de los diafragmas horizontales permiten garantizar que el edificio no presenta riesgos de estabilidad ni se superar los límites reglamentarios de distorsiones frente a solicitaciones sísmicas.

La verificación de las tensiones en los muros a conservar más la revisión estructural de los elementos existentes garantizan que la estructura refuncionalizada resiste con un adecuado margen de seguridad las solicitaciones originadas de la remodelación de la construcción.

\subsection{Recomendaciones finales}

1) Realizar inicialmente un relevamiento de la estructura resistente que nos permita identificar el funcionamiento de la misma ante las acciones de diseño. De esta manera se podrá proyectar adecuadamente la estructura del edificio refuncionalizado.

2) Poner especial atención en los procedimientos constructivos para que las modificaciones, refuerzos y los nuevos elementos estructurales sean razonablemente ejecutables y la obra tenga una factibilidad técnica y económica.

\section{REFERENCIAS}

Payer A., De Nápoli V., Hünicken D., Gattavara H. (2010), Rehabilitación de la estructura de un antiguo hotel para su utilización como banco, $21^{\circ}$ Jornadas Argentinas de Ingeniería Estructural, Buenos Aires, Argentina.

Reglamento CIRSOC 101 (1982), Cargas y Sobrecargas Gravitatorias para el Cálculo de Estructuras de Edificios, Instituto Nacional de Tecnología Industrial, Julio 1982.

Reglamento CIRSOC 201 (1984), Proyecto, Cálculo y Ejecución de Estructuras de Hormigón Armado y Pretensado, Instituto Nacional de Tecnología Industrial, Edición Julio 1982, Actualización 1984.

Reglamento CIRSOC 301 (1982) Proyecto, Cálculo y Ejecución de Estructuras de Acero para Edificios, Instituto Nacional de Tecnología Industrial, Julio 1982

Reglamento INPRES-CIRSOC 103 (1991), Normas Argentinas Para Construcciones Sismorresistentes, Instituto Nacional de Prevención Sísmica, Agosto 1991. 